Review

\title{
Methicillin-resistant Staphylococcus aureus and Staphylococcus pseudintermedius in veterinary medicine
}

\author{
J. Scott Weese ${ }^{\mathrm{a}, *}$, Engeline van Duijkeren ${ }^{\mathrm{b}}$

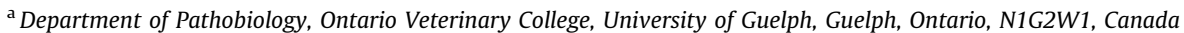 \\ ${ }^{\mathrm{b}}$ Department of Infectious Diseases and Immunology, Faculty of Veterinary Medicine, Utrecht University, Utrecht, The Netherlands
}

\section{A R T I C L E I N F O}

\section{Article history:}

Received 6 November 2008

Received in revised form 9 January 2009

Accepted 27 January 2009

\section{Keywords:}

Antimicrobial resistance

Infectious diseases

Staphylococcus

Zoonoses

\begin{abstract}
A B S T R A C T
Staphylococci are important opportunistic pathogens in most animal species. Among the most relevant species are the coagulase positive species Staphylococcus aureus and Staphylococcus pseudintermedius. Methicillin resistance has emerged as an important problem in both of these organisms, with significant concerns about animal and public health. The relative importance of these staphylococci on different animal species varies, as do the concerns about zoonotic transmission, yet it is clear that both present a challenge to veterinary medicine.
\end{abstract}

(c) 2009 Elsevier B.V. All rights reserved.

\section{Contents}

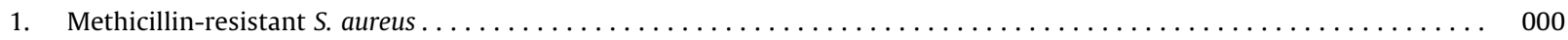

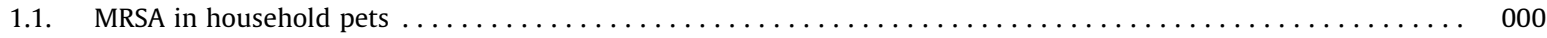

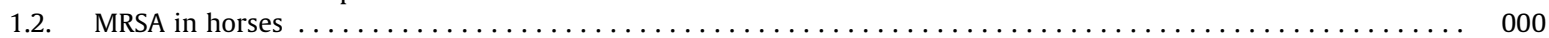

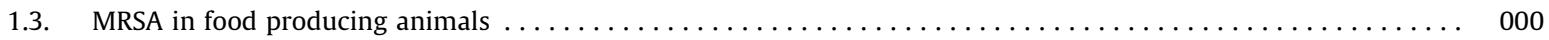

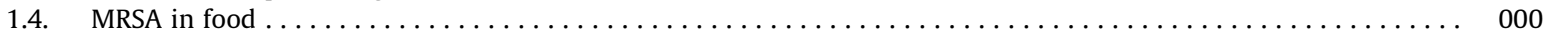

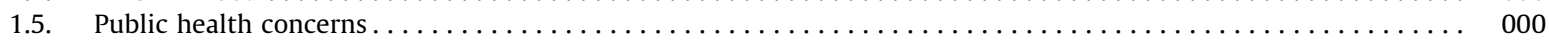

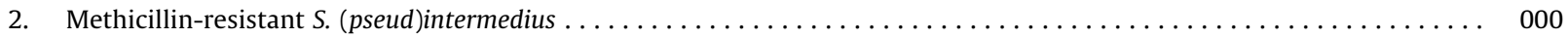

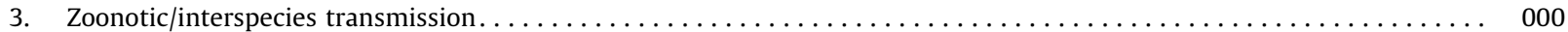

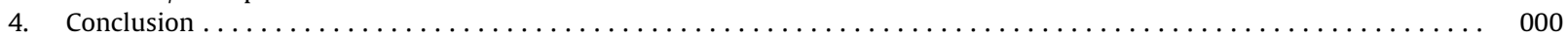

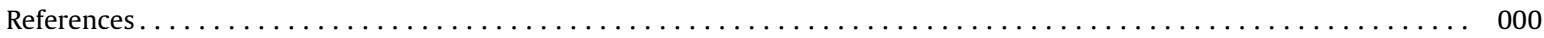

The Genus Staphylococcus consists of a variety of opportunistic pathogens of variable relevance in veterinary medicine. The most clinically relevant staphylococci in veterinary medicine are the coagulase positive Staphylococcus aureus and members of the Staphylococcus intermedius group, particularly Staphylococcus pseudinter-

\footnotetext{
* Corresponding author. Tel.: +1 519824 4120x54064; fax: +1 5198245930 .

E-mail address: jsweese@uoguelph.ca (J.S. Weese).
}

medius. A noted property of staphylococci is their ability to become resistant to antimicrobials. Methicillin resistance is of particular relevance because it is conferred by presence of the mecA gene, which encodes for production of an altered penicillin binding protein (PBP) (PBP2a or PBP2') that has a low affinity for all beta-lactam antimicrobials (penicillins, cephalosporins, carbapenems) (Kwon et al., 2006). Therefore, methicillin-resistant staphylococci are resistant to this broad range of important antimicrobials. The mecA gene resides on a staphylococcal chromosomal cassette (SCCmec). Other resistance genes 
can also be located on this chromosomal cassette or elsewhere in the genome, further limiting treatment options. Methicillin-resistant S. aureus (MRSA) and methicillin-resistant S. pseudintermedius (MRSP) have emerged as significant problems in veterinary medicine, including both animal and public health standpoints. Other methicillin-resistant staphylococci can also cause disease in certain situations, but are less relevant clinically and will not be discussed further.

\section{Methicillin-resistant $S$. aureus}

Methicillin-resistantS. aureus is a tremendous problem in human medicine and is among the most important infections in hospitalized individuals (Klevens et al., 2007). Recently, MRSA has emerged as a significant community-associated pathogen, causing disease in people in the general population, including those that would previously be considered at low risk for infection (Frazee et al., 2005). While MRSA has emerged in animals at a slower rate, this pathogen is now a significant concern in veterinary medicine.

\subsection{MRSA in household pets}

As MRSA has become more prevalent in people in the community, it was perhaps inevitable that exposure of domestic animals to MRSA would occur, particularly household pets, with which many people have close contact. The emergence of MRSA in pets has potentially significant implications on both animal and human health.

Most animals that encounter MRSA have no problems, as evidenced by identification of MRSA colonization in clinically normal animals, but various opportunistic infections can develop. Wound infections, surgical site infections, pyoderma, otitis and urinary tract infections are most commonly reported, but opportunistic infections at various other body sites can occur (Baptiste et al., 2005; Griffeth et al., 2008; Leonard et al., 2006; Morris et al., 2006a,b; Tomlin et al., 1999; Vitale et al., 2006; Weese et al., 2006b). All ages, breed and genders can be affected. There has been minimal investigation of risk factors for MRSA infection. Administration of antimicrobials, particularly fluoroquinolones, appears to be a risk factor for MRSA versus methicillin-susceptible $S$. aureus (MSSA) infection in dogs and cats (Faires, 2008). The implications of MRSA infection, compared to infections caused by other pathogens, in dogs and cats are unclear. There was no difference in survival rate in dogs and cats with MSSA versus MRSA infections in one study (Faires, 2008), although a large percentage of infected animals had pyoderma or otitis, conditions that are not typically associated with mortality. Further study of the prognosis for invasive MRSA infections compared to MSSA or other infections is needed.

As in many other species, MRSA can be found in a small percentage of healthy dogs (Table 1 ). There has been less investigation of colonization in cats, with rates of $0-4 \%$ reported (Abraham et al., 2007; Baptiste et al., 2005; Kottler et al., 2008; Loeffler et al., 2005; Hanselman et al., 2007). Predominant sites of colonization in dogs and cats are not known. Many studies have used combinations of rectal or perineal and nasal swabs, with additional sites evaluated in others. Variable results can be obtained, with some animals positive at only one site. It appears that, at a minimum, a combination of nasal and rectal or perineal swabs is needed for optimal sensitivity. Risk factors for colonization of pets in the community have not been adequately investigated. However, a longitudinal study comparing MRSA acquisition by hospital visitation dogs to dogs that performed nonhospital visitation identified contact with human hospitals and contact with children as significant risk factors for MRSA colonization (Lefebvre et al., in press). Further, among the dogs that visited hospitals, being fed treats by patients and being allowed to lick patients were risk factors for acquisition of MRSA, allowing some inference as to potential modes of transmission.

Typing data strongly support the hypothesis that MRSA in household pets has emerged as a direct result of MRSA in humans. The MRSA strains found in household pets have tended to be those that predominate in people in the region (Baptiste et al., 2005; Grinberg et al., 2008; Leonard et al., 2006; Malik et al., 2006; Moodley et al., 2006; O'Mahony et al., 2005; Strommenger et al., 2006; Weese et al., 2006b) and it is likely that humans are ultimately the source of MRSA in many if not most pets.

There has been limited investigation of the dynamics of MRSA colonization at the individual animal level but there is evidence that colonization is transient in dogs and cats (Vitale et al., 2006; Weese et al., 2006b, 2007; Lefebvre et al., in press), perhaps because $S$. aureus is not naturally a predominant commensal in these species. This is an important aspect because the transient nature of colonization may indicate that active attempts to decolonize pets are not necessary.

Table 1

Studies of the prevalence of MRSA colonization in dogs.

\begin{tabular}{|c|c|c|c|}
\hline Population & Country & Prevalence & Reference \\
\hline Dogs in the community & UK & $0 \%$ & Baptiste et al. (2005) \\
\hline Dogs in the community & UK & $0.4 \%$ & Rich and Roberts (2006) \\
\hline Dogs in the community & China (Hong Kong) & $0.7 \%$ & Boost et al. (2007b) \\
\hline Dogs in the community & Slovenia & $0 \%$ & Vengust et al. (2006) \\
\hline Dogs in the community & United States & $4 \%$ & Kottler et al. (2008) \\
\hline Dogs in the community & United States & $0 \%$ & Griffeth et al. (2008) \\
\hline Veterinary hospital admissions & Denmark & $0 \%$ & Bagcigil et al. (2007) \\
\hline Veterinary hospital admissions & Canada & $0.5 \%$ & Hanselman et al. (2007) \\
\hline Hospitalized dogs & UK & $9 \%$ & Loeffler et al. (2005) \\
\hline Hospital visitation dogs & Canada & $0 \%$ & Lefebvre et al. (2006) \\
\hline
\end{tabular}




\subsection{MRSA in horses}

Initial reports of MRSA infection in horses were largely sporadic infections or small clusters, mainly associated with veterinary hospitals (Hartmann et al., 1997; Seguin et al., 1999; Shimizu et al., 1997), with the general thought that horses were directly infected by colonized humans. Subsequently, there have been reports of larger numbers of MRSA infection internationally, involving both horses in veterinary hospitals and primary community-onset infections. Clinical MRSA infections can occur as sporadic cases or in outbreaks, involving a wide range of opportunistic infections. Joint, incision and skin/soft tissue infections are most common in community-onset cases, with surgical site infections predominating in hospitalized horses (Hartmann et al., 1997; O'Mahony et al., 2005; Seguin et al., 1999; Weese et al., 2005a) (Anderson et al., 2008) but a variety of other infections have been reported, including pneumonia, metritis, omphalophlebitis, sinusitis, bloodstream infection, invasive device infection, osteomyelitis, tenosynovitis, metritis and mastitis (Baptiste et al., 2005; Cuny et al., 2006; Middleton et al., 2005; Shimizu et al., 1997; Weese et al., 2005a) (Anderson et al., 2008). The severity of disease can be quite variable, from mild and superficial infection to aggressive and life-threatening, and there is no evidence that MRSA infections have a different clinical presentation than infections by MSSA or other opportunists. A multicentre study did not identify a significant difference in mortality of MRSA versus MSSA infections, with $84 \%$ of horses with MRSA infections surviving until the time of discharge (Anderson et al., 2008).

The prevalence of MRSA colonization has been investigated in various horse populations, with rates of $0-10.9 \%$ reported in horses in the community and upon admission to veterinary hospitals (Table 2 ) and it is likely that MRSA is endemic in the horse population in many regions. MRSA can cluster on horse farms, with colonization rates of up to $43 \%$ being reported on an individual farm (Weese and Rousseau, 2005). The nasal passages seem to be the primary site of colonization, however objective comparison of different body sites is lacking. While the majority of colonized horses do not develop clinical infections, colonization at the time of admission was identified as a risk factor for development of a clinical MRSA infection in hospitalized horses (Weese et al., 2006c).

Comparison of reports from different areas can be hampered by the use of different typing systems and nomenclatures. There is no standard system currently in place for typing and naming MRSA, and available tests all have advantages and limitations. PFGE is commonly used as it is reproducible, standardized and highly discriminatory. However, analysis can be subjective, some strains are not typable by this method, and it is technically demanding with limitations in. Spa typing, which involves sequence analysis of the $\mathrm{X}$ region of the protein A gene, is a rapid, standardized and objective method that is amenable to higher throughput operation and is being more commonly used. Multilocus sequence typing (MLST) involves sequence analysis of seven housekeeping genes. It is standardized and objective, however it is less discriminatory than PFGE or spa typing and is better for broader temporal or geographic comparisons. Grouping of related sequence types (STs) into clonal complexes (CCs) can be very useful for broader analysis. Additionally, other methods such typing of the staphylococcal chromosomal cassette (SCCmec typing) and detection of Panton Valentine leukocidin (PVL) genes are sometimes used as complementary tests.

Many initial reports of MRSA in horses involved an ST8 clone classified by PFGE as Canadian MRSA-5 or USA500 (Anderson and Weese, 2007; O'Mahony et al., 2005; Weese et al., 2005a,b). This Panton Valentine leukocidin-negative clone, which possesses SCCmecIV, is a human epidemic clone however it only accounts for a small percentage of human infections (Christianson et al., 2007). The predominance of this clone in horses and horse personnel in some regions suggests that this human-origin clone is horse-adapted. Related strains, including ST8 and ST254, have also been identified from horses (Cuny et al., 2006; Moodley et al., 2008), suggesting that related clonal complex 8 strains might be horse-adapted. Recently, there have been reports of colonization and infection with sequence type 398 in horses in Europe (Van den Eede et al., 2009; Witte et al., 2007) and Canada (Tokateloff et al., 2008), including a study that identified ST398 MRSA colonization in $10.9 \%$ of horses admitted to a Belgian teaching hospital (Van den Eede et al., 2009). Considering the recent identification of ST398 in horses and its prevalence in food animals, as discussed below, it is reasonable to suspect that ST398 has entered the horse population directly or indirectly from food animals. It is currently unclear whether this may be an emerging problem in horses.

Risk factors for MRSA colonization and infection have been investigated. Administration of ceftiofur or aminoglycosides was associated with acquisition of MRSA during hospitalization (Weese et al., 2006c). Previous colonization

Table 2

Studies of the prevalence of MRSA colonization in horses.

\begin{tabular}{|c|c|c|c|}
\hline Population & Country & Prevalence & Reference \\
\hline Hospital admissions & Belgium & $10.9 \%$ & Van den Eede et al. (2009) \\
\hline Hospital admissions & Canada & $2.9 \%$ & Weese et al. (2006c) \\
\hline Horses on farms & United States and Canada & $0.7 \%$ & Anderson and Weese (2007) \\
\hline Horses in an equine hospital & United Kingdom & $12 \%$ & Baptiste et al. (2005) \\
\hline Horses on farms & United States and Canada & $4.7 \%$ & Weese et al. (2005b) \\
\hline Horses on farms & Slovenia & $0 \%$ & Vengust et al. (2006) \\
\hline Horses on farms & United Kingdom & $0 \%$ & Baptiste et al. (2005) \\
\hline Horses on farms & The Netherlands & $0 \%$ & Busscher et al. (2006) \\
\hline
\end{tabular}


of the horse, previous identification of colonized horses on the farm, antimicrobial administration within 30 days, admission to the neonatal intensive care unit, and admission to a service other than the surgical service were risk factors for community-associated colonization in another study (Weese and Lefebvre, 2007). Factors associated with clinical infection are unclear.

As with dogs and cats, MRSA colonization in horses appears to be transient in most cases, with decolonization occurring naturally if reinfection is prevented (Weese and Rousseau, 2005).

\subsection{MRSA in food producing animals}

Initial concerns about MRSA and food animals involved pigs as sources of human colonization and infection. While pig farming was previously reported as being a risk factor for nasal S. aureus colonization (Armand-Lefevre et al., 2005; Aubry-Damon et al., 2004) and S. aureus strains from pig farmers tend to be those present in pigs but not non-farmers (Aubry-Damon et al., 2004), little attention was paid to MRSA in pigs until 'unexpected' MRSA infection and colonization were identified in people with contact with pigs in the Netherlands (Voss et al., 2005). This led to identification of a high rate of MRSA colonization (23\%) in pig farmers from the region, which was 760 times that of the general population in that country (Voss et al., 2005). Additionally, an indistinguishable strain was also found among a small group of pigs that were screened for colonization. A unique characteristic of that report was that the isolates were non-typable by smaI PFGE. This led to further studies of MRSA colonization in pigs in different countries, including The Netherlands (de Neeling et al., 2007; Huijsdens et al., 2006; van Duijkeren et al., 2008b), Belgium (Dewaele et al., 2008), Germany (Witte et al., 2007), Canada (Khanna et al., 2007), the United States (Smith et al., 2008) and Singapore (Sergio et al., 2007) (Table 3). Studies on farms and in slaughterhouses have reported high prevalences of colonization at both the pig and farm level. In most studies, the majority, if not all, isolates from pigs have been non-typable by smaI PFGE. These isolates are invariably classified as sequence type 398 (ST398) by multilocus sequence typing and belong to a variety of related spa types, mainly t011, t034, t108 and t1254 (de
Neeling et al., 2007; Huijsdens et al., 2006; Khanna et al., 2007; Schwarz et al., 2008; van Belkum et al., 2008; van Duijkeren et al., 2008b). Different staphylococcal chromosomal cassettes (SCCmec) have been identified, including III, IV, IVa and V (de Neeling et al., 2007; Huijsdens et al., 2006; van Belkum et al., 2008; van Duijkeren et al., 2008b), indicating multiple different emergences of MRSA from MSSA. Despite the predominance of ST398 in pigs internationally, other strains have been found in pigs, including common human clones. While spa types belonging to ST398 were most prevalent in a Canadian study, a common human clone (CMRSA-2/USA100) was also isolated from pigs, suggesting that human-pig transmission can also occur (Khanna et al., 2007).

Risk factors for MRSA colonization of pigs have not been adequately investigated. It has been suggested that the emergence and dissemination of ST398 in pigs has been driven by tetracycline use because ST398 MRSA are almost invariably tetracycline resistant (de Neeling et al., 2007). However, care must be taken with such conclusions since tetracycline resistance is also very common in equine MRSA isolates (Van den Eede et al., 2009; Weese et al., 2005a) yet tetracycline is used sparingly in this species. An increase in the prevalence of colonization among a small group of pigs after tetracycline administration was reported (van Duijkeren et al., 2008b) however this was not statistically significant and it is unclear whether antimicrobial use was the sole or main reason for this increase. Additionally, MRSA colonization was present in pigs in $1 / 10$ farms that did not routinely administer antimicrobials versus $6 / 10$ farms that did. While not statistically significant, these data indicate the need for specific study of the role of antimicrobials as a risk factor.

Despite the high prevalence of colonization, clinical infection with MRSA appears to be rare in pigs. Exudative dermatitis was reported in pigs on one farm (van Duijkeren et al., 2007), while another report described isolation of MRSA from pigs with skin infection, urinary tract infection and metritis, mastitis agalactia syndrome (Schwarz et al., 2008).

Less information is currently available regarding MRSA in cattle, despite the implication of cattle contact as a risk factor for MRSA colonization and infection in humans, as is discussed below. In some respects, the paucity of reports of

Table 3

Studies of MRSA colonization in veterinarians and people with animal contact.

\begin{tabular}{|c|c|c|c|}
\hline Study population & Country $^{\mathrm{a}}$ & Prevalence & Reference \\
\hline Small animal veterinarians & United States & $4.4 \%$ & Hanselman et al. (2006) \\
\hline Large animal veterinarians & United States & $15.6 \%$ & Hanselman et al. (2006) \\
\hline Equine veterinarians & United States & $10.1 \%$ & Anderson et al. (2007) \\
\hline Horse owners and veterinarians & United States and Canada & $13 \%$ & Weese et al. (2005b) \\
\hline Veterinary technicians & United States & $12 \%$ & Hanselman et al. (2006) \\
\hline Veterinarians & Denmark & $3.9 \%$ & Moodley et al. (2008) \\
\hline Veterinarians and veterinary students with livestock contact & The Netherlands & $4.6 \%$ & Wulf et al. (2006) \\
\hline Swine veterinary conference attendees & The Netherlands & $12.5 \%$ & Wulf et al. (2007) \\
\hline Equine veterinary hospital personnel & Canada & $14 \%$ & Weese et al. (2005a) \\
\hline Equine farm personnel & Canada & $12 \%$ & Weese et al. (2005a) \\
\hline Small animal veterinary clinic staff & UK & $18 \%$ & Loeffler et al. (2005) \\
\hline People with veal calf contact & The Netherlands & $32 \%$ & Graveland et al. (2008) \\
\hline Hospitalized people with pig or veal calf contact & The Netherlands & $32 \%$ & van Rijen et al. (2008) \\
\hline
\end{tabular}

${ }^{\text {a }}$ Country where sampling was performed. Some individuals may have been from other countries. 
MRSA infection in cattle is surprising given the considerable role of $S$. aureus as a bovine pathogen and the close contact between people and dairy cattle, and since the first report of MRSA in animals involved mastitis in cattle (Devriese et al., 1972). There have been subsequent reports of MRSA mastitis in dairy cattle (Juhász-Kaszanyitzky et al., 2007; Kwon et al., 2005; Lee, 2003, 2006; Moon et al., 2007; Sabour et al., 2004) yet the incidence of MRSA mastitis and the prevalence of methicillin resistance amongst bovine $S$. aureus isolates appears to be relatively low (Kwon et al., 2005; Lee, 2003; Sabour et al., 2004) so it is unclear whether MRSA is truly a common and important problem in dairy cattle. One limiting factor may be testing, as it is whether most diagnostic laboratories in different regions test bovine mastitis isolates for methicillin resistance.

Minimal information is available about MRSA colonization of healthy cattle. Twenty-eight percent of veal calves were colonized with MRSA in a Dutch study, with spa types corresponding to ST398 (t011, t034, t108, t1197) (Graveland et al., 2008), but studies of other types and ages of cattle are currently lacking. Despite this result and the reported association between cattle contact and ST398 MRSA in humans (van Loo et al., 2007a), it is unclear whether ST398 is the predominant MRSA clone in cattle, particularly in light of PFGE typable MRSA from bovine samples (Juhász-Kaszanyitzky et al., 2007; Kwon et al., 2005), which can be assumed to be distinct from ST398. Further study of MRSA from cattle is required to determine whether ST398 is a common bovine clone and whether it is internationally disseminated in the bovine population as it is in pigs.

While the emergence of MRSA in small animals, and to at least some extent horses, appears to have been associated with humans, ST398 MRSA likely originated in pigs (and perhaps other food animals). Methicillinsusceptible ST398 has been identified retrospectively from collections of porcine $S$. aureus isolates (Guardabassi et al., 2007), and it is likely that ST398 MSSA is a commensal S. aureus in swine and possibly cattle, which has acquired methicillin resistance on multiple occasions.

Unlike in dogs, cats and horses, it is unclear whether longterm colonization is a concern with pigs and cattle. Considering ST398 S. aureus is believed to be a commensal in pigs and perhaps cattle, it may be more likely that longterm colonization could occur, which might complicate MRSA control measures on farms.

There have been limited reports of MRSA infection and colonization in poultry. In one study, MRSA was isolated from three chickens, however the prevalence was not reported (Lee, 2006). Septic arthritis and soft tissue infection have also been described in a small number of chickens (Lee, 2003). Isolation (but not prevalence) of ST398 MRSA types from nares and cloacae of healthy chickens has been recently reported (Nemati et al., 2008). In that study, at least four different SCCmec types were present, indicating multiple different acquisitions of methicillin resistance by ST398 MSSA found in chickens. Whether these originated in chickens or were acquired from other animals is unclear. In another study, MRSA was isolated from the environment in a pigeon slaughterhouse (Losito et al., 2005), however it cannot be stated with certainty that MRSA originated from pigeons versus slaughterhouse personnel.

\subsection{MRSA in food}

The presence of MRSA in food producing animals leads to obvious concerns about MRSA in food, and the potential human health implications. Studies of retail meat have identified MRSA in $0.2-0.5 \%$ of raw chicken samples (Kitai et al., 2005; Kwon et al., 2006), from bovine milk and two types of cheese (although the prevalence was unclear)(Normanno et al., 2007) and 3.1\% of retail pork samples (van Loo et al., 2007b). In the latter study, one isolate was unsurprisingly ST398, however the other was USA300, a clone that has not been reported in pigs or cattle. This brings into question whether MRSA contamination of food is from human or animal sources, and at what point in the food production process contamination occurs.

There are two main areas of concern regarding contaminated foods. One is the potential for development of classical enterotoxin-associated staphylococcal food poisoning, since some MRSA strains can possess enterotoxin genes. There is a report of MRSA food poisoning linked to barbequed pork and coleslaw (Jones et al., 2002), however a food handler was colonized with MRSA and was probably the primary source of contamination. While MRSA staphylococcal food poisoning would be not different than that caused by MSSA, it is still a potential implication of MRSA contamination of food. Additionally, if live MRSA (in addition to enterotoxins) was present in contaminated food, it could be a source of gastrointestinal colonization. The other concern is food as a vehicle for transmission of MRSA, whereby people become colonized or develop extra-intestinal infections from handling contaminated meat. There is a report of foodborne transmission of MRSA in a hospital (Kluytmans et al., 1995). In that report, an outbreak of hospital-associated infections was attributed to a colonized food handler because the outbreak strain was found on a banana that had been peeled by that person and another source of infection was not identified. However, the evidence implicating food as the source of infection appears to be tenuous. The clinical relevance of MRSA contamination of food, particularly for people in the community, is currently unclear.

\subsection{Public health concerns}

There are significant public health concerns about MRSA in animals and food, most of which have only been preliminarily investigated. Most of the concern involves the potential for animals to act as reservoirs of MRSA with subsequent transmission to humans.

Colonization of people in contact with infected or colonized animals has been widely reported for small animals (Boost et al., 2007a; Leonard et al., 2006; Manian, 2003; Sing et al., 2008; van Duijkeren et al., 2005; Vitale et al., 2006; Weese et al., 2006b) and horses (Cuny et al., 2006; Moodley et al., 2006; O'Mahony et al., 2005; Seguin et al., 1999; Weese et al., 2005a,b, 2006a). Most studies have investigated colonization of MRSA, however some 
have involved clinical zoonotic infections. Pets have been implicated as sources of infection for humans in households (Manian, 2003; Sing et al., 2008) however the nature of the studies has been such that evidence is circumstantial and that direction of transmission cannot be proven, even if the same strains are found in humans and animals. This is particularly problematic with household pets since they tend to carry MRSA strains that predominate in humans, so typing results cannot be used to infer the origin of MRSA. Zoonotic infections have also been reported in people working with colonized or infected horses (Weese et al., 2005a, 2006a). Regardless, while information from most studies should be considered preliminary and circumstantial, it is very likely that interspecies transmission can occur in households and on horse farms, in both directions.

There have been numerous studies of MRSA colonization in veterinary personnel (Table 3 ). All such studies should be considered in light of the study population and the expected rates of MRSA colonization in people in the general population, but have generally reported relatively high rates of colonization of veterinary personnel. It cannot be determined with certainty that these colonization rates reflect acquisition of MRSA from animals. However, the higher rates than present in the general population, particularly in equine and food animal veterinarians and similarity between human and animal strains provide further support of possible occupational origin. Typing data provide more evidence, whereby studies of equine veterinarians have reported a predominance of clones associated with horses (i.e. CMRSA-5, CC8) (Weese et al., 2005a,b; Cuny et al., 2006; Hanselman et al., 2007) and those of food animals have reported a predominance of ST398 MRSA (Wulf et al., 2006, 2007), despite those clones being relatively uncommon in the general population. Risk factors have been evaluated within some of these studies. Contact with small animals, cattle or horses, but interestingly not pigs, was a significant risk factor for colonization in one study (Moodley et al., 2008). Having diagnosed a horse with MRSA or having been personally diagnosed with MRSA over the past year were risk factors for colonization of equine veterinarians in another study (Anderson et al., 2007). An important result from the latter study was a statistically significant protective effect of routine hand hygiene following contact with infectious cases and between farms, demonstrating the importance of routine infection control practices such as hand hygiene on MRSA control.

There is significant concern about the role of food animals in MRSA infection and colonization in people, relating primarily to ST398. As described above, the first reports of MRSA in food animals were associated with human infection and colonization (Lewis et al., 2008; van Rijen et al., 2008). Subsequent studies have provided more evidence of the role of pigs, and to a lesser extent other food animals, on MRSA in humans. Dramatic increases in human ST398 rates have been reported in the Netherlands, such as the increase in non-typable (and presumably ST398) MRSA from 0\% in 2002 to $>21 \%$ in 2006 (van Loo et al., 2007a). While changes in surveillance could have had some biasing effect on the high 2006 rate, such a dramatic increase obviously raises significant concern about the potential role of animals in this change. High rates of MRSA colonization have been reported in various groups with livestock contact, including veterinarians, farmers and people living on farms (Table 4). Pig and/or cattle contact has been associated with increased risk of ST398 or nontypable MRSA colonization in people admitted to hospital or in the general population (van Loo et al., 2007a; van Rijen et al., 2008; Vandenbroucke-Grauls and Beaujean, 2006). Some of the studies have identified astounding MRSA colonization rates when compared to the general population, such as Dutch studies reporting colonization of $32 \%$ of people with veal calf contact in the Netherlands (Graveland et al., 2008) and 32\% of people with pig and veal calf contact admitted to hospital (van Rijen et al., 2008), considering the prevalence of colonization in the general human population is less than 1\% (Wulf et al., 2008). Accordingly, it has been recommended that people with pig contact be isolated upon admission to hospital until MRSA screening results are available (VandenbrouckeGrauls and Beaujean, 2006).

Food animal contact has also been associated with clinical MRSA infections. Living on farms or working with animals was identified as a risk factor for ST398 MRSA infection in a Danish study, compared both to patients without MRSA infection and to patients with non-ST398 MRSA infection (Lewis et al., 2008). Most studies have been based in Europe and it is unclear whether a similar situation exists elsewhere. A 20\% colonization rate of pig farmers was found in a Canadian study (Khanna et al., 2007). In that study, both ST398 strains and a common human epidemic clone (Canadian epidemic MRSA-2) were found, and on all farms where a colonized farmer was identified, one or more pigs were found colonized with an indistinguishable strain. Despite the finding of ST398 MRSA in pigs and pig farmers in North America, infections with ST398 are currently rarely identified in North America and it remains to be seen whether ST398 will emerge as an important human pathogen outside Europe.

Table 4

Studies of the prevalence of MRSA colonization in pigs.

\begin{tabular}{|c|c|c|c|}
\hline Population & Country & Prevalence & Reference \\
\hline Pigs in slaughterhouses & The Netherlands & $39 \%$ & de Neeling et al. (2007) \\
\hline Healthy pigs on farms & The Netherlands & $80 \%$ & Huijsdens et al. (2006) \\
\hline Healthy pigs on farms & Canada & $25 \%$ & Khanna et al. (2007) \\
\hline Healthy pigs on farms & United States & $70 \%$ & Smith et al. (2008) \\
\hline Healthy pigs on farms & The Netherlands & $11 \%$ & van Duijkeren et al. (2008b) \\
\hline Healthy pigs on farms & Germany & $13 \%$ & Meemken et al. (2008) \\
\hline Research pig herd & Singapore & $6 \%$ & Sergio et al. (2007) \\
\hline
\end{tabular}




\section{Methicillin-resistant $S$. (pseud)intermedius}

S. intermedius was described as a species in 1976 based on $\mathrm{G}+\mathrm{C}$ content and phenotypic tests (Hajek, 1976). It is part of the normal microflora of the skin and mucosa of dogs and cats (Cox et al., 1988, 1985; Talan et al., 1989b) and has also been found in a wide range of other animals including horses, goats, minks, foxes, raccoons and pigeons. During the past few years, there has been confusion about the classification of $S$. intermedius. In 2005, a novel staphylococcal species, S. pseudintermedius was described based on 16S rRNA gene sequence analysis of isolates from a cat, a dog, a horse and a parrot (Devriese et al., 2005). Recently isolates formerly identified as $S$. intermedius by phenotypic characteristics were reclassified (Sasaki et al., 2007b). The isolates belonging to the $S$. intermedius group were divided into three clusters: $S$. intermedius, S. pseudintermedius and S. delphini based on the nucleotide sequence analysis of the sodA and hsp60 genes (Sasaki et al., 2007b). Bannoehr et al. (2007) investigated 105 isolates of the $S$. intermedius group from 10 countries and three continents by multilocus sequence typing and found a populations structure consistent with that reported by Sasaki et al. (2007b). All canine strains examined in both studies were classified as $S$. pseudintermedius. Therefore, it has been proposed to report all strains from dogs as $S$. pseudintermedius, unless genomic investigations prove that the strain belongs to another related species (Devriese et al., 2009). It must be noted that isolates reported as $S$. intermedius in the literature, especially canine isolates, might in fact be $S$. pseudintermedius, because until recently only phenotypic tests were used to characterize them while molecular methods are necessary to differentiate $S$. intermedius from $S$. pseudintermedius. In this review we use the term $S$. (pseud)intermedius when the isolates previously identified as $S$. intermedius are probably S. pseudintermedius, MRS(P)I for methicillin-resistant $S$. (pseud)intermedius and MRSP for isolates identified as $S$. pseudintermedius.

$S$. (pseud)intermedius can be isolated from the nares, mouth, anus, groin and forehead of healthy dogs and cats as well as from dogs and cats with inflammatory skin disease (Abraham et al., 2007; Griffeth et al., 2008). The anal region and the nasal vestibulum are colonized more frequently than the groin, axilla, forehead, prepuce, vagina, external auditory channel and the interdigital skin in healthy dogs, the anal mucosa being colonized most heavily (Devriese and De Pelsmaecker, 1987). It is an opportunistic pathogen that can cause infections of the skin (pyoderma, otitis externa, wound infections, abscesses) and other body tissues and cavities (Cox et al., 1984; Morris et al., 2006b).

In the past, $S$. (pseud)intermedius isolates were generally reported to be susceptible to beta-lactam antibiotics, but methicillin-resistant $S$. (pseud)intermedius (MRS(P)I) strains are being reported with increasing frequency (Gortel et al., 1999; Piriz et al., 1996; van Duijkeren et al., 2008a; Vengust et al., 2006; Zubeir et al., 2007). Methicillin-resistant $S$. pseudintermedius have been isolated from dogs, cats and humans (Hanselman et al., 2007; Sasaki et al., 2007a; Schwarz et al., 2008; Wettstein et al., 2008). As in MRSA, the methicillin resistance of $S$. pseudintermedius is mediated by the mecA gene.

The prevalence of MRS(P)I colonization has been studied in various dog populations, with rates of $1.5-2 \%$ in dogs in the community and upon admission to veterinary hospitals (Griffeth et al., 2008; Hanselman et al., 2007; Vengust et al., 2006), 0-7\% in dogs with skin disease (Griffeth et al., 2008; Kania et al., 2004; Medleau et al., 1986) and 30\% in dogs at a veterinary clinic in Japan (Sasaki et al., 2007a) (Table 5). One study comparing the prevalence of coagulase positive staphylococci from dogs with healthy and inflamed skin found S. (pseud)intermedius to be by far the most common species from both healthy dogs and dogs with skin disease (Griffeth et al., 2008). The prevalence of MRS(P)I in cats was $4 \%$ in healthy cats whereas no MRS(P)I was found in cats with inflammatory skin disease (Abraham et al., 2007). No MRS(P)I was found among 300 horses in the community in Slovenia (Vengust et al., 2006) and no other reports on MRS(P)I in horses are currently present in the literature indicating that this organism is probably absent or rare in healthy horses. Reports on the prevalence of methicillin resistance among $S$. (pseud)intermedius isolates from small animals vary from 0\% (Medleau et al., 1986; Shimizu et al., 2001; van Duijkeren et al., 2004) to 17\% (Morris et al., 2006b). Multidrug-resistant S. (pseud)intermedius resistant to at least five antimicrobial classes accounted for $23 \%$ of all $S$. (pseud)intermedius isolates from one veterinary dermatology referral clinic in Germany and the PFGE results pointed to the local spread of one clone in the region or nosocomial spread at the clinic (Loeffler et al., 2007). All MRS(P)I positive animals had received antimicrobial therapy. In another study, ten MRS(P)I isolates

Table 5

Studies of the prevalence of MRSP(I) colonization in dogs, cats and horses.

\begin{tabular}{|c|c|c|c|}
\hline Population & Country & Prevalence & Reference \\
\hline Healthy dogs & United States & $1 / 59(2 \%)$ & Griffeth et al. (2008) \\
\hline Healthy dogs & Slovenia & $3 / 200(1.5 \%)$ & Vengust et al. (2006) \\
\hline Veterinary hospital admissions (dogs and cats) & Canada & $4 / 193(2 \%)$ & Hanselman et al. (2007) \\
\hline Dogs with pyoderma & United States & $0 / 210(0 \%)$ & Medleau et al. (1986) \\
\hline Dogs with skin disease & United States & $4 / 59(7 \%)$ & Griffeth et al. (2008) \\
\hline Dogs with pyoderma & United States & $2 / 57(3.5 \%)$ & Kania et al. (2004) \\
\hline Dogs at a veterinary clinic (inpatients and outpatients) & Japan & $17 / 57(30 \%)$ & Sasaki et al. (2007a) \\
\hline Healthy cats & United States & $2 / 50(4 \%)$ & Abraham et al. (2007) \\
\hline Healthy cats & Brazil & $6 / 150(4 \%)$ & Lilenbaum et al. (1999) \\
\hline Cats with skin disease & United States & $0 / 48(0 \%)$ & Abraham et al. (2007) \\
\hline Healthy horses & Slovenia & $0 / 300(0 \%)$ & Vengust et al. (2006) \\
\hline
\end{tabular}


originating from dogs and cats at one German veterinary clinic were identical or closely related which indicates that a single clone was distributed among pets in this clinic and/or in the community (Zubeir et al., 2007).

Bannoehr et al. (2007) investigated 105 isolates of the $S$. intermedius group from different countries and animal species by MLST and found identical or closely related ST in several countries on different continents indicating broad geographic dissemination of the most successful clones. Among the 89 S. pseudintermedius isolates examined over 60 different ST were found, signifying considerable diversity within S. pseudintermedius. However, eBURST (Based Upon Related Sequence Types) analysis showed that MRSP isolates belonged to five distinct ST's (ST29, ST68, ST69, ST70 and ST71). MRSP clones were not shared between Europe and North America. It was postulated that the mecA gene has been acquired several times by different S. pseudintermedius strains. The ST's of clinical human isolates were closely related to commensal canine isolates suggesting zoonotic transmission. MRSP was isolated from $2 \%$ of dogs admitted to a veterinary teaching hospital in Canada, from nasal swabs, but not from rectal or axillary swabs (Hanselman et al., 2007). None of the colonized dogs developed clinical infection during hospitalization. One dogs was retested one month later and was found MRSP negative, however further studies on the duration of colonization of MRSP are needed. All four MRSP isolates had different PFGE patterns suggestive of different sources.

In 2007, MRSP resistant to erythromycin, clindamycin, trimethoprim-sulfamethoxazole, gentamicin and levofloxacin was detected in 17 of 57 (30\%) dogs at a veterinary clinic in Japan and most of the dogs had received antimicrobial agents within the previous six months (Sasaki et al., 2007a). However, further studies are needed in order to identify whether antimicrobial therapy is an important risk factor for the colonization by MRSP. The PFGE patterns of the canine isolates differed and at least three SCCmec types were found and therefore it was postulated that they were not only acquired at this hospital but also in primary veterinary clinics or in the community.

Analysis of 158 isolates from respiratory tract infections and skin/ear/mouth infections from dogs and cats in Germany revealed two canine MRSP infections (Schwarz et al., 2008). Both isolates were resistant to beta-lactams, gentamicin, tetracycline, sulfamethoxazole and one of the isolates was also resistant to chloramphenicol. In Switzerland MRSP carrying the leukocidin gene lukS-I were cultured from three cats with urinary tract infections (Wettstein et al., 2008). All cats had been treated with beta-lactams or fluoroquinolones and the isolates displayed resistance to beta-lactams, fluoroquinolones, tetracyclines, macrolides, lincosamides and streptogramins, chloramphenicol, trimethoprim, gentamicin, kanamycin, neomycin and streptomycin. Multidrug-resistant MRSP isolates represent a challenge for antimicrobial therapy in veterinary medicine because of the limited treatment options in many cases. Further, the potential pressure to use antimicrobials that are important for treatment of serious infections in humans raises ethical questions and creates the potential for scrutiny of (and potentially restriction of) extra-label drug use in veterinary medicine.
Studies on the risk factors associated with MRSP infections in animals are lacking, but are urgently needed. To date there are no reports comparing the clinical presentation or mortality rate between infections caused by methicillin-susceptible and -resistant S. pseudintermedius. In one study MSR(P)I was found to be more common in dogs than in cats. This difference could be explained by the fact that pyoderma and otitis externa were often caused by MRS(P)I and these conditions are much more common in dogs than in cats (Morris et al., 2006b).

The SCCmec elements of MRS(P)I have been reported to be of type III (Campanile et al., 2007; Sasaki et al., 2007a) and type V (Sasaki et al., 2007a). A study investigating the SCCmec type of $15 \mathrm{~S}$. pseudintermedius isolates from dogs found that they harboured two new SCCmec elements named SCCmecII-III (consisting of a combination of SCCmecIII from S. aureus and SCCmecII from S. epidermidis) and SCCmec VII (Descloux et al., 2008).

\section{Zoonotic/interspecies transmission}

An important difference with $S$. aureus is that $S$. (pseud)intermedius colonization is very uncommon in humans even among individuals with frequent contact with animals. In an investigation among 144 healthy veterinary college staff members only one person was colonized with $S$. (pseud)intermedius (Talan et al., 1989c). In an investigation of 3397 coagulase positive staphylococcal isolates from hospitalized patients only two $S$. (pseud)intermedius isolates were identified: one from a healthy carrier and one from pleural fluid, which was thought to be contamination rather than infection (Mahoudeau et al., 1997). Therefore its importance as a zoonotic pathogen is less than that of MRSA. However, several cases of zoonotic transmission of methicillin-susceptible and methicillinresistant $S$. (pseud)intermedius between dogs and humans have been published. The occurrence of S. (pseud)intermedius was investigated in 13 dogs affected by deep pyoderma, their owners and 13 individuals without daily contact with dogs (Guardabassi et al., 2004). The occurrence of $S$. (pseud)intermedius in the owners of dogs affected by deep pyoderma was significantly higher (6/13) than in the control group (1/13) and they often carried the same $S$. (pseud)intermedius strain as their dogs. However, all persons were sampled a second time and were found to be no longer carriers and the dogs had no longer purulent lesions, so probably the direct contact with the lesions is a risk factor for the transmission of the organism to humans. Pottumarthy et al. (2004) reported the isolation of methicillin-susceptible $S$. (pseud)intermedius from four unrelated patients that were initially mistaken for MRSA because of false positive PBP2a latex agglutination tests combined with an error in the interpretation of phenotypic tests. Talan et al. (1989a) re-analyzed 14 isolates from human dog-bite wounds that were originally identified as S. aureus and three (22\%) were found to be S. (pseud)intermedius. This shows that $S$. (pseud)intermedius may be misidentified as $S$. aureus in medical laboratories and therefore its real incidence in humans may be underestimated. Better diagnostic tools, including genotyping, are needed to avoid misidentification in the future. 
S. (pseud)intermedius is a common and potential invasive pathogen of dog-bite wounds in humans. $S$. (pseud)intermedius infections were identified in 6 of 34 dog-bite wounds (18\%) in the United Kingdom (Lee, 1994). In addition $S$. (pseud)intermedius has been associated with bacteraemia (Vandenesch et al., 1995), pneumonia (Gerstadt et al., 1999), ear infections (Kikuchi et al., 2004; Tanner et al., 2000), varicose leg ulcers (Lee, 1994), an infected suture line (Lee, 1994) and a brain abscess (Atalay et al., 2005). In most cases the origin of the organism remained unknown. S. pseudintermedius was cultured from pus and tissue from an infected implantable cardioverterdefibrillator of a 60-year-old patient (Van Hoovels et al., 2006). The isolate was identified by 16 rRNA gene and tuf gene sequence analysis. The source of the infection remained unknown and contact with animals was not investigated. In another case, $S$. (pseud)intermedius was cultured from the ear fluid of a patient with otitis externa and from her pet dog (Tanner et al., 2000). The case reports on zoonotic transmission of methicillin-susceptible $S$. (pseud)intermedius show that the organism has the potential to colonize and infect humans. To date, reports on zoonotic transmission of MRS(P)I are scarce. A MRS(P)I was isolated from a patient with gastric adenocarcinoma who developed bacteremia. However, the origin of the isolate remained unknown because no information on animal contact was available (Campanile et al., 2007). MRS(P)I was also isolated from a patient with pneumonia who had no exposure to dogs (Gerstadt et al., 1999). In 2007, MRSP was detected in 17 dogs and one staff member at a veterinary teaching hospital in Japan (Sasaki et al., 2007a). The human MRSP isolate showed a susceptibility pattern and genotype similar to that some of the dogs suggesting dog-to-human transmission. Nosocomial transmission of methicillin-resistant $S$. (pseud)intermedius was also documented in a private veterinary clinic in the Netherlands (van Duijkeren et al., 2008a). MRS(P)I was cultured from infected surgical wounds of five dogs and one cat over a short period of time and all patients had undergone surgery at the same veterinary clinic. Four of 22 environmental samples and four of seven persons working at the clinic were also MRS(P)I positive. The PFGE profiles of the isolates were indistinguishable, but differed from MRS(P)I isolates from other clinics. It was concluded that the isolates were epidemiologically related and that nosocomial transmission at the clinic had occurred. As the dogs and the cats had had no contact with each other it seemed likely that the veterinary surgeon or the nurses were the source of the wound infections, although the index case was most likely a companion animal as $S$. (pseud)intermedius is seldom isolated from humans. People working at veterinary clinics should be aware of the risk of nosocomial transmission of MRS(P)I. Good hygiene is essential in order to prevent the spread of multidrugresistant isolates in clinical settings.

An other potential route of transmission, although less important than through direct contact, is food as one outbreak of food intoxication associated with $S$. (pseud)intermedius producing type A enterotoxin involving over 265 cases occurred in the United States (Khambaty et al., 1994).

\section{Conclusion}

It is hard to dispute that methicillin-resistant staphylococci will be a considerable challenge for the veterinary profession. Methicillin-resistant staphylococcal infections are important causes of morbidity and mortality in companion animals, and may be involved in zoonotic transmission. Regardless of the actual risk of zoonotic transmission, fear of transmission may have impacts of the human-animal bond and peoples' interaction with their pets. Colonization of companion animals may create significant occupational health risks for veterinary personnel. The emerging problem of MRSA colonization in food producing animals and the links with human infection have an impact on food animal production, occupational health of people that work with food animals and risks of disease of the general population. Scrutiny of food animal management practices, particularly antimicrobial therapy, may result in significant effects on animal production in the future. Similarly, the dissemination of highly drug resistant staphylococci and subsequent use of antimicrobials that are important for treatment of serious infections in humans may increase scrutiny of extra-label drug use practices in companion animals. Overall, the potential impact of methicillin-resistant staphylococci on animal health, human health, veterinary medicine and food animal production is great. This will necessitate a comprehensive investigation of the emergence, dissemination, prevention and control of infection and colonization caused by these important animal and zoonotic pathogens. The close interrelationship between humans and animals with respect to these organisms necessitates coordinated efforts and a broad 'ecological' approach rather than one focusing on individual animal species. Methicillin-resistant staphylococci, particularly MRSA and MRSP represent a significant challenge in veterinary medicine, in terms of both animal and public health. Careful consideration of the epidemiology of MRSA in humans, interaction between humans and animals (both companion animals and food producing animals), antimicrobial use in all species, animal husbandry, animal slaughter and food handling practices and general principles of infection control are required, making this a complex and somewhat daunting area. Extensive clinical, epidemiological and microbiological study, involving animal populations and the animal-human interface is required to better elucidate the role of both MRSA and MRSP in animal disease, to clarify and quantify public health concerns and to develop evidence-based infection prevention and control measures.

\section{Conflict of interest statement}

None of the authors (J. Scott Weese, Engeline van Duijkeren) has a financial or personal relationship with other people or organizations that could inappropriately influence or bias the paper.

\section{References}

Abraham, J., Morris, D., Griffeth, G., Shofer, F., Rankin, S., 2007. Surveillance of healthy cats and cats with inflammatory skin disease for colonization of the skin by methicillin-resistant coagulase-positive 
staphylococci and Staphylococcus schleiferi ssp. schleiferi. Vet. Dermatol. 18, 252-259.

Anderson, M.E.C., Lefebvre, S.L., Rankin, S.C., Aceto, H. Morley, P.S., Caron, J.P., Welsh, R.D., Holbrook, T.C., Moore, B., Taylor, D.R., Weese, J.S., 2008. A prospective study of methicillin-resistant Staphylococcus aureus infections in 115 horses. Equine Vet. J., in press.

Anderson, M., Weese, J., 2007. Evaluation of a real-time polymerase chain reaction assay for rapid identification of methicillin-resistant Staphylococcus aureus directly from nasal swabs in horses. Vet. Microbiol. $122,185-189$.

Anderson, M.E., Lefebvre, S.L., Weese, J.S., 2007. Evaluation of prevalence and risk factors for methicillin-resistant Staphylococcus aureus colonization in veterinary personnel attending an international equine veterinary conference. Vet. Microbiol. 129, 410-417.

Armand-Lefevre, L., Ruimy, R., Andremont, A., 2005. Clonal comparison of Staphylococcus aureus isolates from healthy pig farmers, human controls, and pigs. Emerg. Infect. Dis. 11, 711-714

Atalay, B., Ergin, F., Cekinmez, M., Caner, H., Altinors, N., 2005. Brain abscess caused by Staphylococcus intermedius. Acta Neurochir. 147, 347-348.

Aubry-Damon, H., Grenet, K., Sall-Ndiaye, P., Che, D., Cordeiro, E. Bougnoux, M., Rigaud, E., Le Strat, Y., Lemanissier, V., Armand-Lefèvre, L., Delzescaux, D., Desenclos, J., Liénard, M., Andremont, A., 2004. Antimicrobial resistance in commensal flora of pig farmers. Emerg. Infect. Dis. 10, 873-879.

Bagcigil, F., Moodley, A., Baptiste, K., Jensen, V., Guardabassi, L., 2007. Occurrence, species distribution, antimicrobial resistance and clonality of methicillin- and erythromycin-resistant staphylococci in the nasal cavity of domestic animals. Vet. Microbiol. 121, 307-315.

Bannoehr, J., Ben Zakour, N., Waller, A., Guardabassi, L., van den Broek, A., Thoday, K., Fitzgerald, J., 2007. Population genetic structure of the Staphylococcus intermedius group: insights into agr diversification and the emergence of methicillin-resistant strains. J. Bacteriol. 189, 86858692 .

Baptiste, K., Williams, K., Willams, N., Wattret, A., Clegg, P., Dawson, S., Corkill, J., O'Neill, T., Hart, C., 2005. Methicillin-resistant staphylococci in companion animals. Emerg. Infect. Dis. 11, 1942-1944.

Boost, M., O'donoghue, M., Siu, K., 2007a. Characterisation of methicillinresistant Staphylococcus aureus isolates from dogs and their owners. Clin. Microbiol. Infect. 13, 731-733.

Boost, M.V., O'donoghue, M.M., James, A., 2007b. Prevalence of Staphylococcus aureus carriage among dogs and their owners. Epidemiol. Infect. 136, 1-12.

Busscher, J., van Duijkeren, E., Sloet van Oldruitenborgh-Oosterbaan, M. 2006. The prevalence of methicillin-resistant staphylococci in healthy horses in the Netherlands. Vet. Microbiol. 113, 131-136.

Campanile, F., Bongiorno, D., Borbone, S., Venditti, M., Giannella, M., Franchi, C., Stefani, S., 2007. Characterization of a variant of the SCCmec element in a bloodstream isolate of Staphylococcus intermedius. Microb. Drug Resist. 13, 7-10.

Christianson, S., Golding, G., Campbell, J., Mulvey, M., 2007. Comparative genomics of Canadian epidemic lineages of methicillin-resistant Staphylococcus aureus. J. Clin. Microbiol. 45, 1904-1911.

Cox, H.U., Hoskins, J.D., Newman, S.S., Foil, C.S., Turnwald, G.H., Roy, A.F., 1988. Temporal study of staphylococcal species on healthy dogs. Am. J. Vet. Res. 49, 747-751.

Cox, H.U., Hoskins, J.D., Newman, S.S., Turnwald, G.H., Foil, C.S., Roy, A.F., Kearney, M.T., 1985. Distribution of staphylococcal species on clinically healthy cats. Am. J. Vet. Res. 46, 1824-1828.

Cox, H.U., Newman, S.S., Roy, A.F., Hoskins, J.D., 1984. Species of Staphylococcus isolated from animal infections. Cornell Vet. 74, 124-135.

Cuny, C., Kuemmerle, J., Stanek, C., Willey, B., Strommenger, B., Witte, W. 2006. Emergence of MRSA infections in horses in a veterinary hospital: strain characterisation and comparison with MRSA from humans. Euro Surveill. 11, 44-47.

de Neeling, A., van den Broek, M., Spalburg, E., van Santen-Verheuvel, M., Dam-Deisz, W., Boshuizen, H., van de Giessen, A., van Duijkeren, E., Huijsdens, X., 2007. High prevalence of methicillin resistant Staphylococcus aureus in pigs. Vet. Microbiol. 122, 366-372.

Descloux, S., Rossano, A., Perreten, V., 2008. Characterization of new staphylococcal cassette chromosome mec (SCCmec) and topoisomerase genes in fluoroquinolone- and methicillin-resistant Staphylococcus pseudintermedius. J. Clin. Microbiol. 46, 1818-1823.

Devriese, L., Vancanneyt, M., Baele, M., Vaneechoutte, M., De Graef, E., Snauwaert, C., Cleenwerck, I., Dawyndt, P., Swings, J., Decostere, A., Haesebrouck, F., 2005. Staphylococcus pseudintermedius sp. nov., a coagulase-positive species from animals. Int. J. Syst. Evol. Microbiol. 55, 1569-1573.

Devriese, L.A., De Pelsmaecker, K., 1987. The anal region as a main carrier site of Staphylococcus intermedius and Streptococcus canis in dogs. Vet. Rec. 121, 302-303.
Devriese, L.A., Hermans, K., Baele, M., Haesebrouck, F., 2009. Staphylococcus pseudintermedius versus Staphylococcus intermedius. Vet Microbiol. 133, 206-207.

Devriese, L.A., Van Damme, L.R., Fameree, L., 1972. Methicillin (cloxacillin)-resistant Staphylococcus aureus strains isolated from bovine mastitis cases. Zentralbl. Vet. Reihe B 19, 598-605.

Dewaele, I., De Man, I., Stael, A., Delputte, P., Butaye, P., Vlaemynck, G., Herman, L., Heyndrickx, M., Rasschaert, G., 2008. Methicillin-resistant Staphylococcus aureus (MRSA) in Belgian pig farms. In: ASM Conference on Antimicrobial Resistance in Zoonotic Bacteria and Foodborne Pathogens, Copenhagen, Denmark, p. 23.

Faires, M, 2008. Evaluation of methicillin-resistant Staphylococcus aureus and characterization of Staphylococcus pseudintermedius in dogs and cats. MSc Thesis, University of Guelph, Guelph, Canada.

Frazee, B., Lynn, J., Charlebois, E., Lambert, L., Lowery, D., PerdreauRemington, F., 2005. High prevalence of methicillin-resistant Staphylococcus aureus in emergency department skin and soft tissue infections. Ann. Emerg. Med. 45, 311-320.

Gerstadt, K., Daly, J.S., Mitchell, M., Wessolossky, M., Cheeseman, S.H., 1999. Methicillin-resistant Staphylococcus intermedius pneumonia following coronary artery bypass grafting. Clin. Infect. Dis. 29, 218-219.

Gortel, K., Campbell, K.L., Kakoma, I., Whittem, T., Schaeffer, D.J., Weisiger, R.M., 1999. Methicillin resistance among staphylococci isolated from dogs. Am. J. Vet. Res. 60, 1526-1530.

Graveland, H., Wagenaar, J.A., Broekhuizen-Stins, M.J., OostingSchothorst, I., Schoormans, A.H., van Duijkeren, E., Huijsdens, X. Mevius, D., Heederik, D., 2008. Methicillin-resistant Staphylococcus aureus (MRSA) in veal calf farmers and veal calves in The Netherlands. In: ASM Conference on Antimicrobial Resistance in Zoonotic Bacteria and Foodborne Pathogens, Copenhagen, Denmark, pp. 62-63.

Griffeth, G.C., Morris, D.O., Abraham, J.L., Shofer, F.S., Rankin, S.C., 2008. Screening for skin carriage of methicillin-resistant coagulase-positive staphylococci and Staphylococcus schleiferi in dogs with healthy and inflamed skin. Vet. Dermatol. 19, 142-149.

Grinberg, A. Kingsbury, D.D., Gibson, I.R., Kirby, B.M., Mack, H.J., Morrison, D., 2008. Clinically overt infections with methicillin-resistant Staphylococcus aureus in animals in New Zealand: a pilot study. N. Z. Vet. J. $56,237-242$

Guardabassi, L., Loeber, M., Jacobson, A., 2004. Transmission of multiple antimicrobial-resistant Staphylococcus intermedius between dogs affected by deep pyoderma and their owners. Vet. Microbiol. 98 , 23-27.

Guardabassi, L., Stegger, M., Skov, R., 2007. Retrospective detection of methicillin resistant and susceptible Staphylococcus aureus ST398 in Danish slaughter pigs. Vet. Microbiol. 122, 384-386.

Hajek, V., 1976. Staphylococcus intermedius, a new species isolated from animals. Int. J. Syst. Bacteriol. 26, 401-408.

Hanselman, B., Kruth, S., Rousseau, J., Low, D., Willey, B., McGeer, A., Weese, J., 2006. Methicillin-resistant Staphylococcus aureus colonization in veterinary personnel. Emerg. Infect. Dis. 12, 1933-1938.

Hanselman, B.A., Kruth, S., Weese, J.S., 2007. Methicillin-resistant staphylococcal colonization in dogs entering a veterinary teaching hospital. Vet. Microbiol. 126, 277-281.

Hartmann, F.A., Trostle, S.S., Klohnen, A.A., 1997. Isolation of methicillinresistant Staphylococcus aureus from a postoperative wound infection in a horse. J. Am. Vet. Med. Assoc. 211, 590-592.

Huijsdens, X., van Dijke, B., Spalburg, E., van Santen-Verheuvel, M., Heck, M., Pluister, G., Voss, A., Wannet, W., de Neeling, A., 2006. Community-acquired MRSA and pig-farming. Ann. Clin. Microbiol. Antimicrob. 5,26

Jones, T., Kellum, M., Porter, S., Bell, M., Schaffner, W., 2002. An outbreak of community-acquired foodborne illness caused by methicillin-resistant Staphylococcus aureus. Emerg. Infect. Dis. 8, 82-84.

Juhász-Kaszanyitzky, E., Jánosi, S., Somogyi, P., Dán, A., van der Graaf-van Bloois, L., van Duijkeren, E., Wagenaar, J., 2007. MRSA transmission between cows and humans. Emerg. Infect. Dis. 13, 630-632.

Kania, S., Williamson, N., Frank, L., Wilkes, R., Jones, R., Bemis, D., 2004. Methicillin resistance of staphylococci isolated from the skin of dogs with pyoderma. Am. J. Vet. Res. 65, 1265-1268.

Khambaty, F.M., Bennett, R.W., Shah, D.B., 1994. Application of pulsedfield gel electrophoresis to the epidemiological characterization of Staphylococcus intermedius implicated in a food-related outbreak. Epidemiol. Infect. 113, 75-81.

Khanna, T., Friendship, R., Dewey, C., Weese, J.S., 2007. Methicillin resistant Staphylococcus aureus colonization in pigs and pig farmers. Vet. Microbiol. 128, 298-303.

Kikuchi, K., Karasawa, T., Piao, C., Itoda, I., Hidai, H., Yamaura, H., Totsuka, K., Morikawa, T., Takayama, M., 2004. Molecular confirmation of transmission route of Staphylococcus intermedius in mastoid cavity infection from dog saliva. J. Infect. Chemother. 10, 46-48. 
Kitai, S., Shimizu, A., Kawano, J., Sato, E., Nakano, C., Uji, T., Kitagawa, H., 2005. Characterization of methicillin-resistant Staphylococcus aureus isolated from retail raw chicken meat in Japan. J. Vet. Med. Sci. 67, 107-110.

Klevens, R.M., Morrison, M.A., Nadle, J., Petit, S., Gershman, K., Ray, S. Harrison, L.H., Lynfield, R., Dumyati, G., Townes, J.M., Craig, A.S., Zell, E.R., Fosheim, G.E., McDougal, L.K., Carey, R.B., Fridkin, S.K., Investigators, A.B.C.s.A.M., 2007. Invasive methicillin-resistant Staphylococcus aureus infections in the United States. JAMA 298, 1763-1771.

Kluytmans, J., van Leeuwen, W., Goessens, W., Hollis, R., Messer, S. Herwaldt, L., Bruining, H., Heck, M., Rost, J., van Leeuwen, N., 1995. Food-initiated outbreak of methicillin-resistant Staphylococcus aureus analyzed by pheno- and genotyping. J. Clin. Microbiol. 33, 1121-1128.

Kottler, S., Middleton, J.R., Weese, J.S., Cohn, L., 2008. Prevalence of Staphylococcus aureus and MRSA carriage in three populations. In: 26th Annual Conference of the American College of Veterinary Internal Medicine, San Antonio, TX.

Kwon, N., Park, K., Jung, W., Youn, H., Lee, Y., Kim, S., Bae, W., Lim, J., Kim, J., Kim, J., Hong, S., Park, Y., 2006. Characteristics of methicillin resistant Staphylococcus aureus isolated from chicken meat and hospitalized dogs in Korea and their epidemiological relatedness. Vet. Microbiol. 117, 304-312.

Kwon, N.H., Park, K.T., Moon, J.S., Jung, W.K., Kim, S.H., Kim, J.M., Hong, S.K., Koo, H.C., Joo, Y.S., Park, Y.H., 2005. Staphylococcal cassette chromosome mec (SCCmec) characterization and molecular analysis for methicillin-resistant Staphylococcus aureus and novel SCCmec subtype IVg isolated from bovine milk in Korea. J. Antimicrob. Chemother. 56, 624-632.

Lee, J., 1994. Staphylococcus intermedius isolated from dog-bite wounds. J. Infect. 29, 105

Lee, J., 2003. Methicillin (Oxacillin)-resistant Staphylococcus aureus strains isolated from major food animals and their potential transmission to humans. Appl. Environ. Microbiol. 69, 6489-6494.

Lee, J., 2006. Occurrence of methicillin-resistant Staphylococcus aureus strains from cattle and chicken, and analyses of their mecA, mecR1 and mecl genes. Vet. Microbiol. 114, 155-159.

Lefebvre, S.L., Reid-Smith, R., Weese, J.S. Incidence of acquisition of methicillin-resistant Staphylococcus aureus, Clostridium difficile and other healthcare-associated pathogens by dogs and participate in animal-assisted interventions. J. Am. Vet. Med. Assoc., in press.

Lefebvre, S.L., Waltner-Toews, D., Peregrine, A.S., Reid-Smith, R., Hodge, L., Arroyo, L.G., Weese, J.S., 2006. Prevalence of zoonotic agents in dogs visiting hospitalized people in Ontario: implications for infection control. J. Hosp. Infect. 62, 458-466.

Leonard, F., Abbott, Y., Rossney, A., Quinn, P., O'Mahony, R., Markey, B., 2006. Methicillin-resistant Staphylococcus aureus isolated from a veterinary surgeon and five dogs in one practice. Vet. Rec. 158, $155-159$.

Lewis, H.C., Mølbak, K., Reese, C., Aarestrup, F.M., Selchau, M., Sørum, M., Skov, R.L., 2008. Pigs as source of methicillin-resistant Staphylococcus aureus CC398 infections in humans, Denmark. Emerg. Infect. Dis. 14, 1383-1389.

Lilenbaum, W., Esteves, A.L., Souza, G.N., 1999. Prevalence and antimicrobial susceptibility of staphylococci isolated from saliva of clinically normal cats. Lett. Appl. Microbiol. 28, 448-452.

Loeffler, A., Boag, A., Sung, J., Lindsay, J., Guardabassi, L., Dalsgaard, A., Smith, H., Stevens, K., Lloyd, D., 2005. Prevalence of methicillinresistant Staphylococcus aureus among staff and pets in a small animal referral hospital in the UK. J. Antimicrob. Chemother. 56, 692-697.

Loeffler, A., Linek, M., Moodley, A., Guardabassi, L., Sung, J.M., Winkler, M., Weiss, R., Lloyd, D.H., 2007. First report of multiresistant, mecApositive Staphylococcus intermedius in Europe: 12 cases from a veterinary dermatology referral clinic in Germany. Vet. Dermatol. $18,412-421$

Losito, P., Vergara, A., Muscariello, T., Ianieri, A., 2005. Antimicrobial susceptibility of environmental Staphylococcus aureus strains isolated from a pigeon slaughterhouse in Italy. Poult. Sci. 84, 1802-1807.

Mahoudeau, I., Delabranche, X., Prevost, G., Monteil, H., Piemont, Y., 1997. Frequency of isolation of Staphylococcus intermedius from humans. J. Clin. Microbiol. 35, 2153-2154.

Malik, S., Coombs, G., O’Brien, F., Peng, H., Barton, M., 2006. Molecular typing of methicillin-resistant staphylococci isolated from cats and dogs. J. Antimicrob. Chemother. 58, 428-431.

Manian, F.A., 2003. Asymptomatic nasal carriage of mupirocin-resistant, methicillin-resistant Staphylococcus aureus (MRSA) in a pet dog associated with MRSA infection in household contacts. Clin. Infect. Dis. 36, e26-e28.

Medleau, L., Long, R.E., Brown, J., Miller, W.H., 1986. Frequency and antimicrobial susceptibility of Staphylococcus species isolated from canine pyodermas. Am. J. Vet. Res. 47, 229-231.
Meemken, D., Cuny, C., Witte, W., Eichler, U., Staudt, R., Blaha, T., 2008. Occurrence of MRSA in pigs and in humans involved in pig production-preliminary results of a study in the northwest of Germany. DTW Dtsch. Tierarztl. Wochenschr. 115, 132-139.

Middleton, J., Fales, W., Luby, C., Oaks, J., Sanchez, S., Kinyon, J., Wu, C., Maddox, C., Welsh, R., Hartmann, F., 2005. Surveillance of Staphylococcus aureus in veterinary teaching hospitals. J. Clin. Microbiol. 43, 2916-2919.

Moodley, A., Nightingale, E.C., Stegger, M., Nielsen, S.S., Skov, R.L., Guardabassi, L., 2008. High risk for nasal carriage of methicillin-resistant Staphylococcus aureus among Danish veterinary practitioners. Scand. J. Work Environ. Health 34, 151-157.

Moodley, A., Stegger, M., Bagcigil, A., Baptiste, K., Loeffler, A., Lloyd, D., Williams, N., Leonard, N., Abbott, Y., Skov, R., Guardabassi, L., 2006. spa typing of methicillin-resistant Staphylococcus aureus isolated from domestic animals and veterinary staff in the UK and Ireland. J. Antimicrob. Chemother. 58, 1118-1123.

Moon, J.S., Lee, A.R., Kang, H.M., Lee, E.S., Kim, M.N., Paik, Y.H., Park, Y.H., Joo, Y.S., Koo, H.C., 2007. Phenotypic and genetic antibiogram of methicillin-resistant staphylococci isolated from bovine mastitis in Korea. J. Dairy Sci. 90, 1176-1185.

Morris, D., Mauldin, E., O'Shea, K., Shofer, F., Rankin, S., 2006a. Clinical, microbiological, and molecular characterization of methicillinresistant Staphylococcus aureus infections of cats. Am. J. Vet. Res. 67, 1421-1425.

Morris, D., Rook, K., Shofer, F., Rankin, S., 2006b. Screening of Staphylococcus aureus, Staphylococcus intermedius, and Staphylococcus schleiferi isolates obtained from small companion animals for antimicrobial resistance: a retrospective review of 749 isolates (2003-04). Vet. Dermatol. 17, 332-337.

Nemati, M., Hermans, K., Lipinska, U., Denis, O., Deplano, A., Struelens, M., Devriese, L.A., Pasmans, F., Haesebrouck, F., 2008. Antimicrobial resistance of old and recent Staphylococcus aureus isolates from poultry: first detection of livestock-associated methicillin-resistant strain ST398. Antimicrob. Agents Chemother. 52, 3817-3819.

Normanno, G., Corrente, M., La Salandra, G., Dambrosio, A., Quaglia, N., Parisi, A., Greco, G., Bellacicco, A., Virgilio, S., Celano, G., 2007. Methicillin-resistant Staphylococcus aureus (MRSA) in foods of animal origin product in Italy. Int. J. Food Microbiol. 117, 219-222.

O'Mahony, R., Abbott, Y., Leonard, F., Markey, B., Quinn, P., Pollock, P., Fanning, S., Rossney, A., 2005. Methicillin-resistant Staphylococcus aureus (MRSA) isolated from animals and veterinary personnel in Ireland. Vet. Microbiol. 109, 285-296.

Piriz, S., Valle, J., Mateos, E.M., de la Fuente, R., Cid, D., Ruiz-Santaquiteria, J.A., Vadillo, S., 1996. In vitro activity of fifteen antimicrobial agents against methicillin-resistant and methicillin-susceptible Staphylococcus intermedius. J. Vet. Pharmacol. Ther. 19, 118-123.

Pottumarthy, S., Schapiro, J., Prentice, J., Houze, Y., Swanzy, S., Fang, F., Cookson, B., 2004. Clinical isolates of Staphylococcus intermedius masquerading as methicillin-resistant Staphylococcus aureus. J. Clin. Microbiol. 42, 5881-5884.

Rich, M., Roberts, L., 2006. MRSA in companion animals. Vet. Rec. 159, 535-536.

Sabour, P., Gill, J., Lepp, D., Pacan, J., Ahmed, R., Dingwell, R., Leslie, K., 2004. Molecular typing and distribution of Staphylococcus aureus isolates in Eastern Canadian dairy herds. J. Clin. Microbiol. 42, 3449-3455.

Sasaki, T., Kikuchi, K., Tanaka, Y., Takahashi, N., Kamata, S., Hiramatsu, K., 2007a. Methicillin-resistant Staphylococcus pseudintermedius in a veterinary teaching hospital. J. Clin. Microbiol. 45, 1118-1125.

Sasaki, T., Kikuchi, K., Tanaka, Y., Takahashi, N., Kamata, S., Hiramatsu, K., 2007b. Reclassification of phenotypically-identified Staphylococcus intermedius strains. J. Clin. Microbiol. 45, 2770-2778.

Schwarz, S., Kadlec, K., Strommenger, B., 2008. Methicillin-resistant Staphylococcus aureus and Staphylococcus pseudintermedius detected in the BfT-GermVet monitoring programme 2004-2006 in Germany. J. Antimicrob. Chemother. 61, 282-285.

Seguin, J.C., Walker, R.D., Caron, J.P., Kloos, W.E., George, C.G., Hollis, R.J., Jones, R.N., Pfaller, M.A., 1999. Methicillin-resistant Staphylococcus aureus outbreak in a veterinary teaching hospital: potential humanto-animal transmission. J. Clin. Microbiol. 37, 1459-1463.

Sergio, D., Koh, T., Hsu, L., Ogden, B., Goh, A., Chow, P., 2007. Investigation of meticillin-resistant Staphylococcus aureus in pigs used for research. J. Med. Microbiol. 56, 1107-1109.

Shimizu, A., Kawano, J., Yamamoto, C., Kakutani, O., Anzai, T., Kamada, M., 1997. Genetic analysis of equine methicillin-resistant Staphylococcus aureus by pulsed-field gel electrophoresis. J. Vet. Med. Sci. 59, 935-937.

Shimizu, A., Wakita, Y., Nagase, S., Okabe, M., Koji, T., Hayashi, T., Nagase, N., Sasaki, A., Kawano, J., Yamashita, K., Takagi, M., 2001. Antimicro- 
bial susceptibility of Staphylococcus intermedius isolated from healthy and diseased dogs. J. Vet. Med. Sci. 63, 357-360.

Sing, A., Tuschak, C., Hörmansdorfer, S., 2008. Methicillin-resistant Staphylococcus aureus in a family and its pet cat. N. Engl. J. Med. 358, $1200-1201$.

Smith, T.C., Male, M.J., HArper, A.L., Moritz-Korolev, E., Kroeger, J.S., Diekema, D.J., Herwaldt, L.A., 2008. Isolation of methicillin-resistant Staphylococcus aureus (MRSA) from swine in the midwestern United States. In: International Conference on Emerging Infectious Diseases, Atlanta, GA, p. 10.

Strommenger, B., Kehrenberg, C., Kettlitz, C., Cuny, C., Verspohl, J., Witte, W., Schwarz, S., 2006. Molecular characterization of methicillin-resistant Staphylococcus aureus strains from pet animals and their relationship to human isolates. J. Antimicrob. Chemother. 57, 461-465.

Talan, D.A., Goldstein, E.J., Staatz, D., Overturf, G.D., 1989a. Staphylococcus intermedius: clinical presentation of a new human dog bite pathogen. Ann. Emerg. Med. 18, 410-413.

Talan, D.A., Staatz, D., Staatz, A., Goldstein, E.J., Singer, K., Overturf, G.D., 1989b. Staphylococcus intermedius in canine gingiva and canineinflicted human wound infections: laboratory characterization of a newly recognized zoonotic pathogen. J. Clin. Microbiol. 27, 78-81.

Talan, D.A., Staatz, D., Staatz, A., Overturf, G.D., 1989c. Frequency of Staphylococcus intermedius as human nasopharyngeal flora. J. Clin. Microbiol. 27, 2393.

Tanner, M., Everett, C., Youvan, D., 2000. Molecular phylogenetic evidence for noninvasive zoonotic transmission of Staphylococcus intermedius from a canine pet to a human. J. Clin. Microbiol. 38, 1628-1631.

Tokateloff, N., Manning, S.T., Weese, J.S., Campbell, J., Rothenburger, J. Reid-Smith, R., 2008. Prevalence of methicillin-resistant Staphylococcus aureus colonization in horses in Saskatchewan, Alberta and British Columbia. Can. Vet. J., in press.

Tomlin, J., Pead, M., Lloyd, D., Howell, S., Hartmann, F., Jackson, H., Muir, P., 1999. Methicillin-resistant Staphylococcus aureus infections in 11 dogs. Vet. Rec. 144, 60-64.

van Belkum, A., Melles, D.C., Peeters, J.K., van Leeuwen, W.B., van Duijkeren, E., Huijsdens, X.W., Spalburg, E., de Neeling, A.J., Verbrugh, H.A., MRSA-SOM, D.W.P.o.S.a.R.o., 2008. Methicillin-resistant and -susceptible Staphylococcus aureus sequence type 398 in pigs and humans. Emerg. Infect. Dis. 14, 479-483.

Van den Eede, A., Martens, A., Lipinska, U., Struelens, M., Deplano, A. Denis, O., Haesebrouck, F., Gasthuys, F., Hermans, K., 2009. High occurrence of methicillin-resistant Staphylococcus aureus ST398 in equine nasal samples. Vet. Microbiol. 133, 138-144.

van Duijkeren, E., Box, A., Heck, M., Wannet, W., Fluit, A., 2004. Methicillin-resistant staphylococci isolated from animals. Vet. Microbiol. 103, 91-97.

van Duijkeren, E., Houwers, D.J., Schoormans, A., Broekhuizen-Stins, M.J., Ikawaty, R., Fluit, A.C., Wagenaar, J.A., 2008a. Transmission of methicillin-resistant Staphylococcus intermedius between humans and animals. Vet. Microbiol. 128, 213-215.

van Duijkeren, E., Ikawaty, R., Broekhuizen-Stins, M., Jansen, M., Spalburg, E., de Neeling, A., Allaart, J., van Nes, A., Wagenaar, J., Fluit, A., 2008b. Transmission of methicillin-resistant Staphylococcus aureus strains between different kinds of pig farms. Vet. Microbiol. 126, 383-389.

van Duijkeren, E., Jansen, M.D., Flemming, S.C., et al., 2007. Methicillinresistant Staphylococcus aureus in pigs with exudative epidermitis. Emerg. Infect. Dis. 13, 1408-1410.

van Duijkeren, E., Wolfhagen, M.J., Heck, M.E., Wannet, W.J., 2005. Transmission of a Panton-Valentine leucocidin-positive, methicillin-resistant Staphylococcus aureus strain between humans and a dog. J. Clin. Microbiol. 43, 6209-6211.

Van Hoovels, L., Vankeerberghen, A., Boel, A., Van Vaerenbergh, K., De Beenhouwer, H., 2006. First case of Staphylococcus pseudintermedius infection in a human. J. Clin. Microbiol. 44, 4609-4612.

van Loo, I., Huijsdens, X.W., Tiemersma, E., de Neeling, A.J., van de SandeBruinsma, N., Beaujean, D., Voss, A., Kluytmans, J., 2007a. Emergence of methicillin-resistant Staphylococcus aureus of animal origin. Emerg. Infect. Dis. 13, 1834-1839.

van Loo, I.H., Diederen, B.M., Savelkoul, P.H., Woudenberg, J.H., Roosendaal, R., van Belkum, A., Lemmens-den Toom, N., Verhulst, C., van Keulen, P.H., Kluytmans, J.A., 2007b. Methicillin-resistant Staphylo- coccus aureus in meat products, the Netherlands. Emerg. Infect. Dis. $13,1753-1755$.

van Rijen, M.M., Van Keulen, P.H., Kluytmans, J.A., 2008. Increase in a Dutch hospital of methicillin-resistant Staphylococcus aureus related to animal farming. Clin. Infect. Dis. 46, 261-263.

Vandenbroucke-Grauls, C.M., Beaujean, D.J., 2006. Methicillin-resistant Staphylococcus aureus in pig breeders and cattle breeders. Ned. Tijdschr. Geneeskd. 150, 1710-1712.

Vandenesch, F., Célard, M., Arpin, D., Bes, M., Greenland, T., Etienne, J., 1995. Catheter-related bacteremia associated with coagulase-positive Staphylococcus intermedius. J. Clin. Microbiol. 33, 2508-2510.

Vengust, M., Anderson, M., Rousseau, J., Weese, J., 2006. Methicillinresistant staphylococcal colonization in clinically normal dogs and horses in the community. Lett. Appl. Microbiol. 43, 602-606.

Vitale, C., Gross, T., Weese, J., 2006. Methicillin-resistant Staphylococcus aureus in cat and owner. Emerg. Infect. Dis. 12, 1998-2000.

Voss, A., Loeffen, F., Bakker, J., Klaassen, C., Wulf, M., 2005. Methicillinresistant Staphylococcus aureus in pig farming. Emerg. Infect. Dis. 11, 1965-1966.

Weese, J., Archambault, M., Willey, B., Hearn, P., Kreiswirth, B., Said-Salim, B., McGeer, A., Likhoshvay, Y., Prescott, J., Low, D., 2005a. Methicillinresistant Staphylococcus aureus in horses and horse personnel, 20002002. Emerg. Infect. Dis. 11, 430-435.

Weese, J., Caldwell, F., Willey, B., Kreiswirth, B., McGeer, A., Rousseau, J., Low, D., 2006a. An outbreak of methicillin-resistant Staphylococcus aureus skin infections resulting from horse to human transmission in a veterinary hospital. Vet. Microbiol. 114, 160-164.

Weese, J., Dick, H., Willey, B., McGeer, A., Kreiswirth, B., Innis, B., Low, D., 2006b. Suspected transmission of methicillin-resistant Staphylococcus aureus between domestic pets and humans in veterinary clinics and in the household. Vet. Microbiol. 115, 148-155.

Weese, J., Rousseau, J., 2005. Attempted eradication of methicillin-resistant staphylococcus aureus colonisation in horses on two farms. Equine Vet. J. 37, 510-514.

Weese, J., Rousseau, J., Traub-Dargatz, J., Willey, B., McGeer, A., Low, D. 2005b. Community-associated methicillin-resistant Staphylococcus aureus in horses and humans who work with horses. J. Am. Vet. Med. Assoc. 226, 580-583.

Weese, J., Rousseau, J., Willey, B., Archambault, M., McGeer, A., Low, D. 2006c. Methicillin-resistant Staphylococcus aureus in horses at a veterinary teaching hospital: frequency, characterization, and association with clinical disease. J. Vet. Intern. Med. 20, 182-186.

Weese, J.S., Faires, M., Rousseau, J., Bersenas, A.M., Mathews, K.A., 2007. Cluster of methicillin-resistant Staphylococcus aureus colonization in a small animal intensive care unit. J. Am. Vet. Med. Assoc. 231,1361-1364.

Weese, J.S., Lefebvre, S.L., 2007. Risk factors for methicillin-resistant Staphylococcus aureus colonization in horses admitted to a veterinary teaching hospital. Can. Vet. J. 48, 921-926.

Wettstein, K., Descloux, S., Rossano, A., Perreten, V., 2008. Emergence of methicillin-resistant Staphylococcus pseudintermedius in Switzerland three cases of urinary tract infections in cats. Schweiz. Arch. Tierheilkd. 150, 339-343.

Witte, W., Strommenger, B., Stanek, C., Cuny, C., 2007. Methicillin-resistant Staphylococcus aureus ST398 in humans and animals, Central Europe. Emerg. Infect. Dis. 13, 255-258.

Wulf, M., van Nes, A., Eikelenboom-Boskamp, A., de Vries, J., Melchers, W. Klaassen, C., Voss, A., 2006. Methicillin-resistant Staphylococcus aureus in veterinary doctors and students, the Netherlands. Emerg. Infect. Dis. 12, 1939-1941.

Wulf, M.W., Sørum, M., van Nes, A., Skov, R., Melchers, W.J., Klaassen, C.H., Voss, A., 2007. Prevalence of methicillin-resistant Staphylococcus aureus among veterinarians: an international study. Clin. Microbiol. Infect. 14, 519-521.

Wulf, M.W., Tiemersma, E., Kluytmans, J., Bogaers, D., Leenders, A.C., Jansen, M.W., Berkhout, J., Ruijters, E., Haverkate, D., Isken, M., Voss, A., 2008. MRSA carriage in healthcare personnel in contact with farm animals. J. Hosp. Infect. 70, 186-190.

Zubeir, I., Kanbar, T., Alber, J., Lämmler, C., Akineden, O., Weiss, R., Zschöck, M., 2007. Phenotypic and genotypic characteristics of methicillin/oxacillin-resistant Staphylococcus intermedius isolated from clinical specimens during routine veterinary microbiological examinations. Vet. Microbiol. 121, 170-176. 